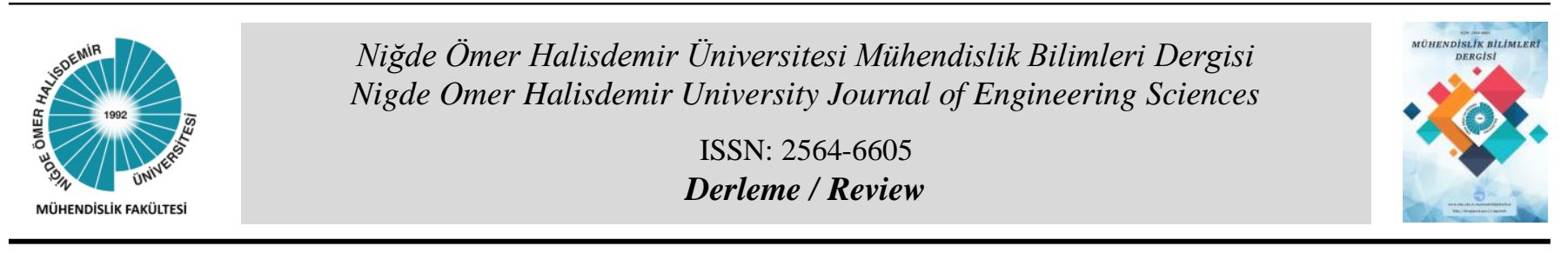

\title{
ARITILMIŞ KENTSEL ATIKSULARIN SULAMADA KULLANIMINDA MIKKROKİRLETICIILERIN OLUŞTURABİLECEĞİ RİSKLER
}

\author{
Aynur YAŞAR ${ }^{1, *}$ (D), Esra CAN DOĞAN² (iD \\ ${ }^{1}$ Kocaeli Üniversitesi, Yapı İşleri ve Teknik Daire Başkanlı̆̆l, 41380, İzmit, Kocaeli, Türkiye \\ ${ }^{2}$ Kocaeli Üniversitesi, Mühendislik Fakültesi, Çevre Mühendisliği Bölümü, 41380, İzmit, Kocaeli, Türkiye
}

\begin{abstract}
ÖZET
Teknolojinin hızlı gelişimi ile birlikte kentsel, tarımsal, endüstriyel ve rekreasyonel su ihtiyacının artış gösterdiği son dönemde arıtılmış kentsel atıksuların sulama amaçlı kullanımı büyük bir potansiyel su kaynağı olarak görülmektedir. Ancak özellikle ikincil arıtılmış atıksularda yeterli düzeyde giderilemeyen mikrokirleticilerin varlığı yeni bir endişe kaynağıdır. Bu tür atıksuların ileri arıtım teknikleri ile üçüncül arıtım yapıldıktan sonra sulamada kullanımı halk ve çevre sağlığı tehditlerini gidermek için zaruri bir ihtiyaçtır. Bu konuda arıtılmış atıksulardaki mikrokirleticilerden kaynaklanan çevresel riskler göz önüne alınmamaktadır. Ayrıca bu kirleticilerle ilgili deşarj standartlarının kabulündeki karmaşalar, atıksuların yeniden kullanımı/geri kazanımı önündeki engeller arasında yer almaktadır. Bu çalışma, kentsel arıtılmış atıksuların sulamada kullanımında endişe yaratan mikrokirleticiler, bu kirleticilerle ilgili yasal yönergeler, mikrokirleticilerin çevrede yaratacağ 1 riskler ile bunların su ortamından uzaklaştırılması için uygulanan arıtma seçenekleri üzerine odaklanmıştır. Bu kapsamdaki literatür çalışmaları, mikrokirleticilerin ileri arıtma proseslerinin yanı sıra yenilikçi hibrit uygulamalar ile yüksek verimlerde giderildikten sonra arıtılmış kentsel atıksuların sulamaya uygun hale getirilebileceğini vurgulamaktadır.
\end{abstract}

Anahtar kelimeler: İleri oksidasyon, Kentsel atıksu, Sulama, Mikrokirleticiler, Membran Prosesler, Risk değerlendirme.

\section{THE RISK OF MICROPOLLUTANTS WHEN THE USE OF TREATED URBAN WASTEWATER IN IRRIGATION}

\begin{abstract}
The use of treated urban wastewater for irrigation has been seen as a major potential water source in the recent years, when the need for urban, agricultural, industrial and recreational water has increased with the rapid development of technology. However, the presence of micropollutants is a new concern, which cannot be adequately removed, especially in secondary treated wastewater. The use of this type of wastewater for irrigation after applying advanced tertiary treatment techniques is an essential requirement to eliminate public and environmental health threats. The environmental risks due to presence of micropollutants in the treated wastewater have not taken into consideration. Furthermore the confusion in accepting the discharge standards related to these pollutants pose an obstacle for reuse/recovery of wastewater. The current study focused on micro-pollutants that cause concern in the use of urban treated wastewater in irrigation, legal guidelines regarding these pollutants, the risks that micro-pollutants will create in the environment and the treatment options applied to remove of micropollutants from the water environment. The studies investigated for this purposes indicate that treated urban wastewater can be made suitable to irrigation after removal at high efficiencies with innovative hybrid applications as well as advanced treatment processes of micropollutants.
\end{abstract}

Keywords: Advanced Oxidation, Urban Wastewater, Irrigation, Micropollutants, Membrane Processes, Risk Assessment.

\section{GíRiş}

Hızlı nüfus artışı, kentleşme, sulamaya açılan alanların genişlemesi, endüstrileşme ve küresel iklim değişikliği gibi nedenlerle su kaynakları üzerine baskılar artmıştır. Su kaynaklarının sürdürülebilir kullanımı üzerinde giderek artan tehditleri azaltabilmek için yeni yaklaşımlara ihtiyaç duyulmaktadır. Arıtılmış atıksuların yeniden kullanımı/geri kazanımı, mevcut su kaynaklarının korunması ile birlikte birçok alanda su ihtiyacının karşılanması için yeni bir kaynak yaratmaktadır.

Kentsel atıksular, evsel atıksu ya da evsel atıksuyun endüstriyel atıksu ve/veya yağmur suyu ile karışımını ifade etmektedir [1]. Kentsel atıksular genellikle konvansiyonel sistemler ile arıtılarak alıcı ortamlara deşarj edilmektedir. Ancak arıtılmış

* Sorumlu yazar / Corresponding author, e-posta / e-mail: aynurfis@kocaeli.edu.tr

Geliş / Recieved: 06.02.2020 Kabul / Accepted: 03.07.2020 doi: 10.28948/ngumuh.685509 
atıksuların, içeriğinde risk teşkil eden mikrokirleticilerin etkili bir şekilde giderilerek yeniden kullanıma/geri kazanıma uygun hale getirilmesi için ileri arıtım teknikleri ile arıtılması gerekmektedir.

Birçoğu sudaki organizmalar için akut veya kronik olarak toksik olabilen, insanlar ve hayvanlar için sağlık riski oluşturabilen 200'den fazla farklı kimyasal bileşik, belediye atıksu arıtma tesisi ikincil çıkış sularında tanımlanmaktadır. Bu kimyasalların çoğu (farmasotikler ve kişisel bakım ürünleri, endokrin bozucu bileşikler, vb.) kolayca bozunmayan ve bu nedenle uzun vadeli çevresel etkilere neden olabilen mikrokirleticilerdir [2]. Su geri kazanımı ve yeniden kullanımının en büyük sorunlarından biri, halkı arıtılmış atık sularda bulunan kimyasal ve mikrobiyal kirleticilere maruz bırakma riskidir. Bu riskleri gidermenin en iyi yolu ise atıksuların üçüncül arıtımıdır [3],[4].

$\mathrm{Bu}$ çalı̧̧mada, öncelikle arıtılmış kentsel atıksularda bulunan, halk ve çevre sağlığı bakımından endişe yaratan mikrokirleticiler ve bu kirleticilerin çevreye deşarjı ile ilgili ulusal ve uluslararası yönergeler incelenmiştir. Daha sonra arıtılmış kentsel atıksuların sürdürülebilir su yönetimi kapsamında sulama amaçlı geri kazanımı ve yeniden kullanımının gerekliliği vurgulanarak, sulama suyu geri kazanımı için mikrokirleticilerin giderimini hedefleyen arıtma seçenekleri ve bunların hibrit uygulamalarını içeren çalışmalar değerlendirilmiş̧ir. Ayrıca arıtılmış kentsel atıksuların sulamada kullanımında mikrokirleticilerin çevrede yaratacağı olası riskler literatürden araştırılarak derlenmiştir.

\section{ARITILMIŞ KENTSEL ATIKSULAR}

Kanalizasyon sistemlerine ya da diğer alıcı ortamlara boşaltılan evsel atıksular, endüstriyel atıksular ve/veya yağmursularının çeşitli fiziksel ve biyokimyasal süreçlerden geçirilmesi ile oluşan atıksular arıtılmış kentsel atıksulardır. Bu kapsamdaki evsel atıksular ise yaygın olarak yerleşim bölgelerinden ve çoğunlukla evsel faaliyetler ile insanların günlük yaşam faaliyetlerinin yer aldığı çeşitli hizmet sektörlerinden kaynaklanmaktadır [1]. Arıtılmış kentsel atıksular yüksek hacim, uygulanabilirlik ve iyi bilinen kalite özelliklerinden dolayı sürdürülebilir su yönetimi için en iyi sulama suyu kaynakları arasında gösterilmektedir [2]-[4]. Ancak bu kaynaklarda bulunan ve konvansiyonel sistemler ile yeterli oranlarda giderilemeyen birçok mikrokirletici grubu insan ve çevre sağlığı üzerinde kısa ve uzun vadede negatif etkilere yol açacak potansiyele sahiptir [3]-[8]. Konvansiyonel aktif çamur sistemi (AÇS) veya membran biyolojik reaktör (MBR) ile arıtım sonrasında çıkış sularında ve oluşan arıtma çamurlarında özellikle farmasotikler gibi mikrokirleticiler ng- $\mu \mathrm{g}$ arasında değişen konsantrasyonlarda bulunmaktadır [9],[10]. Ulusal ve uluslararası hakemli dergilerde yayınlanan 78 adet makalede belediye atıksu arıtma tesisleri ham giriş suyunda analjezikler ve steroidal olmayan anti-enflamatuar ilaçlar (NSAID) gibi mikrokirletici konsantrasyonlarının, $1.60 \mathrm{ng} / \mathrm{L}$ ila $373 \mu \mathrm{g} / \mathrm{L}$ arasında olduğu belirlenmiştir. Antibiyotik konsantrasyonları ise $1.0 \mathrm{ng} / \mathrm{L}$ ile 32 $\mu \mathrm{g} / \mathrm{L}$ aralığında tespit edilmiştir [11].

\subsection{Arıtılmıș Kentsel Atıksulardaki Mikrokirleticiler}

Farklı su kaynaklarında, atıksularda ve arıtılmış atıksularda yeni ortaya çıkan kirleticilerin varlığı dikkat çekmektedir. USEPA bu kirleticileri, yasal statüsü olmayan ve çevre-insan sağlığı üzerine olan etkileri tam olarak anlaşılamayan yeni kimyasallar olarak tanımlamaktadır [12]. Geri kazanılmış sularda da, ng/L düzeyinde kalan, yüksek çeşitlilikte ve karmaşık fizikokimyasal özelliklerle karakterize olan kalıcı kimyasallar vardır ki bu kimyasallar mikrokirleticiler olarak tanımlanmaktadır [13].

Farmasotikler ve kişisel bakım ürünleri (PPCP), endokrin bozucular (EB), fitalatlar, polisiklik aromatik hidrokarbonlar (PAH), poliklorlubifeniller (PCB), pestisitler, bitki büyüme düzenleyiciler, solventler, radyonükleidler, yüzey aktif maddeler, ağır metaller, mikroplastikler, fosfor alev geciktiriciler gibi pek çok grup bileşik kentsel atıksulardaki mikrokirleticiler arasında yer almaktadır [7],[12]. Mikrokirleticiler atıksu arıtma tesislerinde suda çözünerek, çamura absorbe olarak veya hidroliz, oksidasyon ve fotodegredasyon gibi bir çeşit kimyasal veya biyokimyasal süreçte bozunarak çevreye karışmaktadırlar (Şekil 1). Birçok biyolojik arıtma tesisinde mikrokirleticiler kolaylıkla enzimatik reaksiyonlar ile biyodönüşüme uğrarlar [14].

Atıksular ile ilgili yapılan birçok çalışmada en sık incelenen mikrokirletici bileşikler ibuprofen, diklofenak, naproksen, ketoprofen ve asetaminofen, trimetoprim, sülfametoksazol, eritromisin, siprofloksasin, endokrin bozucu bileşikler ve diğer farmasotiklerdir [11]. Wang ve diğ. [7], Çin'de bulunan belediye atıksu arıtma tesislerine ait ikincil arıtma giriş ve çıkış suları ile ileri arıtma çıkış sularından 32 atıksu numunesinde toplam 43 yarı uçucu organik kimyasal madde tespit etmişlerdir. İkincil ve ileri arıtılmış nihai atıksularda ise elde edilen kimyasal madde miktarları sırasıyla 196 ve $145^{\prime}$ tir. İkincil ve nihai atıksulardaki konsantrasyonlarına bağlı olarak tespit edilen zararlı mikrokirletici grupları, PAH'ler (2-metilnaftalen, fluoranten, piren, naftalen ve fenantren), fosfor alev geciktiriciler [tributil fosfat (TBP), tris(2-kloroetil) fosfat (TCEP) ve tris (1,3-dikloro2-propil) fosfat (TDCP)], fitalatlar [bis(2-etilheksil)fitalat (DEHP)], benzotiyazoller [benzotiyazol, 2-(metiltiyo)-benzotiyazol ve $2(3 \mathrm{H})$-benzotiazolon] ve fenol şeklindedir. 


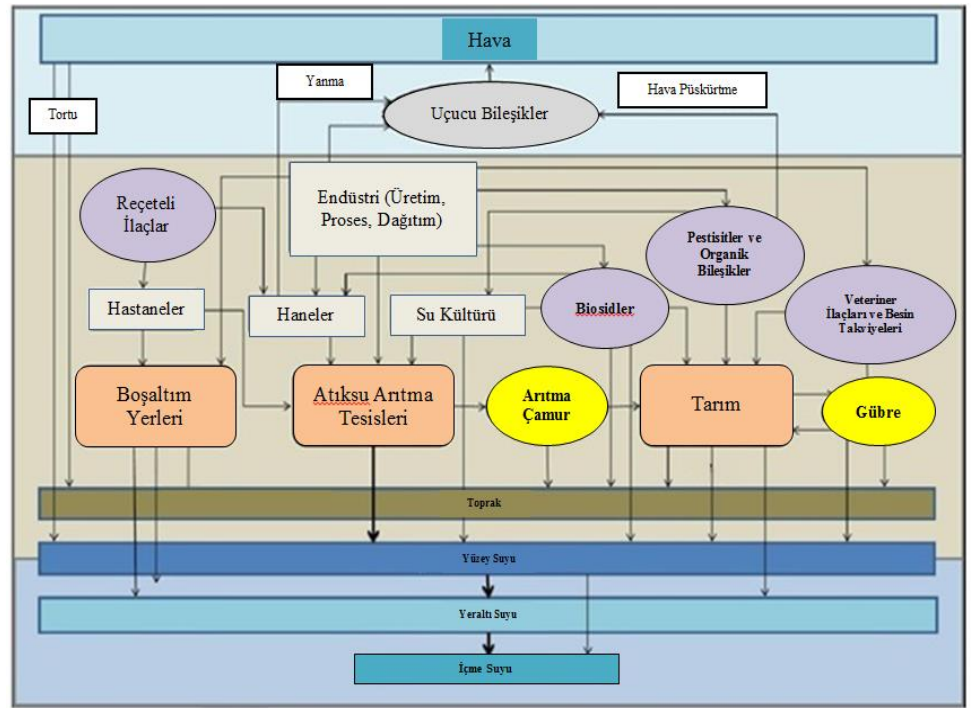

Şekil 1. Mikrokirleticilerin çevreye giriş yolları [14]

Mikrokirleticiler arasında yer alan mikroplastikler, birincil (primer) ve ikincil (sekonder) mikroplastikler şeklinde iki grupta sinıflandırılır [15],[16]. Özel olarak 5mm'den küçük boyutta üretilen plastik parçacıklarına birincil mikroplastikler denir [17],[18]. Günümüzde hemen hemen tüm dünyada yasaklı olan mikroboncuklar, makyaj, el işi ve tekstil malzemelerinde aşırı miktarda kullanılan simler, endüstriyel üretim peletleri ve geri dönüştürülmüş plastik peletler gibi doğrudan oluşan mikroplastikler birincil mikroplastikler arasındadır [16]. Birçok kişisel bakım ve kozmetik ürününde birincil mikroplastikler kullanılmaktadır. Daha büyük plastiklerin zamanla ve çeşitli etkilerle aşınarak parçalanması neticesinde oluşan mikroplastikler ise ikincil mikroplastiklerdir [18]. Plastik eşyaların dökülmüş parçaları, sentetik tekstil ürünlerinden kopan mikrolifler, ulaşımdan kaynaklanan araç lastiği döküntüleri, hava tozlarındaki sentetik partiküller ikincil mikroplastikler arasında sayılabilir [16]. Atıksularda bulunan mikroplastikler, farmasotikler ve patojen organizmalar gibi zararlı ajanların adsorbe edilmesiyle daha tehlikeli hale gelebilirler [15]. Mikroplastik konulu çalışmaların çoğu, okyanuslardaki plastiklerin \%80'i topraklardan geldiği için tatlı su ve karasal ekosistemlere odaklanmıştır [17].

\subsection{Mikrokirleticilerle İlgili Yasal Yönergeler}

Dünya geneline baktı̆̆ımızda, bugüne kadar mikrokirleticilerin çoğu için deşarj yönergeleri ve standartları oluşturulamamıştır. Bununla birlikte, AB Su Çerçeve Direktifi 2000/60/EC, Ek X ile 45 öncelikli madde veya madde grubunun bir listesi çıarılmıştır. Bu liste, su ekolojisinin korunması amacıyla kalite hedefinin çıkarılması için metalleri, böcek ilaçlarını, fitalatları, PAH'leri ve endokrin bozucu gibi mikrokirleticileri kapsamaktadır [19]. Ülkemizde bu maddeler için çevre kalite standartları, ilk olarak 30/11/2012 tarih ve 28483 sayılı resmi gazetede yayımlanan "Yerüstü Su Kalitesi Yönetmeliği"nde yer almıştır [20]. 10.08.2016 tarih ve 29797 sayılı resmi gazetede yapılan değişikliklerle ismi de "Yüzeysel Su Kalitesi Yönetimi Yönetmeliği" olarak değiştirilen bu yönetmelikte nehirler/göller ile kıyı ve geçiş suları için mikrokirleticilere ait yıllık ortalama ve maksimum izin verilebilir çevre kalite standartları bulunmaktadır. Yerüstü su kaynakları için belirli kirletici adı altında yer alan; su kütlesini, kalitesini olumsuz yönde etkileyebilecek miktarda deşarj edilen madde veya madde gruplarını içeren 250 adet kirletici ve bunlara ait çevresel kalite standartları, yönetmelikte Ek V-Tablo 4'te verilmektedir. Ayrıca yerüstü su kaynakları için 45 adet öncelikli madde ve bunlara ilişkin çevresel kalite standartları da Ek V-Tablo 5'te belirtilmiştir [21].

Ayrıca, Avrupa Birliği çapında izlemeye yönelik maddelerin bir izleme listesi, 20 Mart 2015 tarih ve 2015/495/AB sayılı kararda rapor edilmiştir. Bu mikrokirleticiler iki ilaç [diklofenak ve sentetik hormon 17- $\alpha$-etinilestradiol (EE2)], bir doğal hormon [17- $\beta$-estradiol (E2)], üç makrolid antibiyotik (azitromisin, klaritromisin ve eritromisin), diğer doğal hormon estron (E1), bazı pestisitler (metiokarb, oksadiazon, imidakloprid, tiyakloprid, tiyametoksam, klotianidin, asetamiprid ve triallat), bir UV filtresi (2-etilheksil-4-metoksisinamat) ve yaygın olarak gıda katkı maddesi olarak kullanılan bir antioksidan (2,6-di-tertbutil-4-metilfenol) olarak siralanabilir [22].

\subsection{Arıtılmış Kentsel Atıksuların Sulama Amaçlı Geri Kazanımı/Yeniden Kullanımı}

Su kaynaklarındaki azalmalara bağlı olarak ihtiyaç ve rekabetin gün geçtikçe artması kaçınılmazdır. Uluslararası tarımsal araştırma üzerine bir danışma grubunun tahminlerine göre, 2.7 milyon insanın 2025 yılına kadar su kıtlığı olan bölgelerde hayat sürdüreceği beklenmektedir [23]. Su kıtlığı nüfus artışı, yaşam standartlarının yükselmesi, iklim değişikliği, 
endüstrileşme, tarım ve insan faaliyetlerinden dolayı bir sorun haline gelmiştir [24]-[26]. Özellikle kurak ve yarı kurak bölgelerde su ihtiyacının tatmin edici ölçüde temiz su kaynaklarından karşılanmasındaki zorluklardan dolayı global ölçekte su kıtlı̆̆ 1 artmakta ve büyük bir problem haline gelmekte, bu bakımdan sulama suyu kaynağı olarak atıksu arıtma proseslerinden geri dönüştürülmüş su kullanımı önemli bir strateji olarak dikkat çekmektedir [27]-[34]. Bunun yanısıra belediye atıksularına göre daha düşük organik kirletici ve patojen içeriğine sahip gri suların arıtımı ve yeniden kullanımı planları da Avustralya ve Akdeniz ülkeleri gibi su stresli bölgelerde giderek yaygınlaşmaktadır [35]. Birleşik Arap Emirlikleri'nde (BAE) Sharjah ve diğer şehirlerde özellikle peyzaj sulama için atıksuyun yeniden kullanımı, ülkenin su kıtlığını hafifletmek ve çevresel sürdürülebilirliği teşvik etmek için bir su yönetimi stratejisi olarak yaygın olarak uygulanmaktadır [36].

Son yıllarda zorlayıcı AB düzenlemelerinden dolayı kentsel arıtılmış atıksuların kalitesinin geliştirilmesi zorunlu hale gelmiştir. Ayrıca endüstri, tarım ve kentsel tüketim gibi pek çok sektörde yüksek kalitede suya olan ihtiyaç artmıştır. Bu bakımdan atıksuların ve/veya ikincil arıtma çıkış sularının geri kazanımı ve yeniden kullanımı, sürdürülebilir kentsel su yönetimi yaratmak ve su kaynaklarını korumak için hassas, ekonomik ve güvenilir özellikte bir araç olarak kabul edilmektedir [2],[26],[37],[38]. Bu konuda Amerika, Japonya ve Avustralya suyun yeniden kullanımı ile ilgili sayıları hızla artan proje geliştirmektedir. Avrupa ve Akdeniz Bölgeleri gibi yetersiz su dengesine sahip alanlarda da çeşitli uygulamalar mevcuttur [39]-[41]. Avrupa Birliği ve üye devletleri ise sürdürülebilir bir su yönetimi süreci sağlamak için başarılı bir şekilde önlemler almaktadır. 1991-2025 yılları arasında Avrupa'da yeniden kullanım için arıtılmış belediye atıksularının kullanımının 2 katına çıkması beklenmektedir. Türkiye atıksuyun yeniden kullanımı ve uygulaması için büyük potansiyele sahiptir. Yeterince sosyal farkındalık olmasına rağmen, politika ve yasaların eksikliği, yeniden kullanım uygulamalarının önündeki ana engeldir [8].

Bugüne kadar arıtılmış kentsel atıksuların kullanımı için ortak uygulama alanı tarımsal sulama iken [39], son yıllarda membran teknolojilerin kullanıldığı su geri dönüşüm projeleri arasında akiferin beslenmesi, kentsel, endüstriyel, rekreasyonel ve çevresel kullanımlar, soğutma içeren endüstrilerde proses suyu eldesi, dolaylı olarak yangın suyu, tuvaletlerde geri kazanım, doğrudan içme suyu olarak geri kazanım alternatifleri ve bunların kombinasyonlarını içeren uygulamalar da ilgi çekmektedir [2],[8],[42]-[45]. Ancak araştırmalar göstermektedir ki; global ölçekte sadece atıksularda değil doğal sularda ve arıtılmış atıksularda bile kimyasal ve mikrobiyal kirleticilerin yanı sıra var olan toksik kirleticiler halk sağlığı açısından tehlike yaratmaktadır. $\mathrm{Bu}$ kirleticiler kentsel, tarımsal ve endüstriyel atıksu kaynaklarından ve konvansiyonel ikincil arıtma ile arıtılmış evsel atıksulardan genellikle yetersiz arıtma yoluyla su kaynaklarına karışmaktadırlar [23],[44].

\section{SULAMA SULARINDAKİ MIKROKIRLETICILERIN ÇEVRESEL RISSKLERI}

Çeşitli patojenler (viral, bakteriyel, parazitik protozoa ve helmintler) ve mikrokirleticiler (farmasotikler, dezenfeksiyon yan ürünleri, pestisitler, metaller vb.) deri yoluyla alındığında, solunduğunda veya emildiğinde birçok riski beraberinde getirmektedir. Bu patojenler ve kimyasallar, geri kazanılmış suda bulunursa akut hastalıktan kronik hastalıklara ve ölümlere kadar bir dizi sağlık sonucuna neden olabilmektedir [8]. Bazı farmasotik sınıfları, örneğin antibiyotikler mikroorganizma genomlarında uzun süreli ve geri dönüşümsüz değişikliklere neden olduğundan, su kaynaklarında antibiyotik birikimi potansiyel bir tehlikedir. Bu nedenle su ortamından uygun ve daha etkili farmasotik eliminasyonu oldukça önemlidir [10].

Atıksuların yeniden kullanımında çok farklı risk türleri olduğundan, risk yönetimi süreci karmaşıklığı arttırmaktadır [26]. Özellikle geri kazanılmış suda bulunan geniş yelpazedeki mikrokirleticilerle ilişkili sağlık riskleri bakımından gerekli yeniden kullanım kriterleri yerine getirilse dahi artan geri kazanılmış su kullanımının güvenliği önem teşkil etmektedir [13]. PPCP'ler toplumsal sağlığın ayrılmaz bir parçasıdır. Ancak bu mikrokirleticilerin arıtılmış atıksular da dahil olmak üzere çeşitli çevresel alanlardaki varlıkları, olası insan ve ekolojik sağlık etkileriyle ilgili endişelere yol açmaktadır. Ayrıca atıksuyun yeniden kullanımında insan sağlığı risk değerlendirmesi ile ilgili çalışma sayısı oldukça sınırlıdır [36]. Atıksulardaki PPCP'lerin konsantrasyonu arttıkça ekotoksisite ve insan toksisitesi etkileri de artmaktadır [47].

Mikrokirleticiler sınıfında yer alan mikroplastikler katkı malzemesi içermeleri, toksik kirleticileri adsorplayabilmeleri, canlılar tarafindan besin zannedilerek yutulabilmeleri, atıksu arıtma tesislerinde tamamıla giderilememeleri, atmosferde ve su kaynaklarında kolayca taşınmaları ve doğada zor yok olmaları gibi özelliklerinden dolayı çevre ve sağlık açısından büyük tehlike arz etmektedir. Bu kirleticiler çeşitli canlılar tarafından bünyelerine alındıktan sonra sindirim, boşaltım, üreme ve büyüme sistemlerinde ciddi problemler yaşanmaktadır. Bunun yanısıra mikron boyutundaki plastikler, organik kirleticileri çok iyi adsorplayabildiğinden, bu kirleticilerin besin zinciri yoluyla bir üstte bulunan canlılara aktarılmasına bir vasıta olabilmektedir. Bununla birlikte, nanoplastikler daha kolay emilir ve suda yaşayan türlerde ve diğer hayvanlarda beyin, karaciğer ve diğer dokularda birikebilir [16]. PCB'ler gibi kalıcı organik kirleticiler (KOK) mikroplastiklere adsorbe edilerek ortam konsantrasyonlarından 1 milyon kat daha yüksek konsantrasyonlara ulaşabilir ve bu bileşikler organizmalar içinde daha fazla desorbe edilebilir, bu da daha yüksek trofik seviyelerde KOK biyoakümülasyonunu şiddetlendirir [18].

Yapılan çalışmalar daha çok mikrokirleticilerin biyolojik etkilerine (biyolüminesans inhibisyonu, fotosentez inhibisyonu, suda yaşayan organizmalar üzerindeki olumsuz etkiler, endokrin bozulma etkileri, genotoksisite vb.) ve ekolojik tehditlerine odaklanmıştır. Bununla birlikte, geri kazanılmış suların yeniden kullanımı sırasında tespit edilen çok çeşitli mikrokirleticilere maruz kalmanın neden olduğu olası sağlık riskleri hakkında çok az bilgi vardır. Geri kazanılmış suyun yeniden kullanımı 
sırasında insan sağlığı üzerindeki mikrokirletici etkisinin ihmal edilmesi, bu maddelerin tespit edilmesindeki zorluklara, insan sağlığına ilişkin toksisite verilerinin bulunmamasına ve değerlendirme yöntemlerindeki eksikliklere bağlanabilir. Fizikokimyasal özelliklerine dayanarak geri kazanılmış su elde etmek için gerekli arıtma sistemlerinde mikrokirleticilerin uzaklaştırılmasının iyileştirilmesi ve potansiyel sağlık riskinin azaltılması mümkün olabilir [13].

Semerjian ve diğ. [36] yaptıkları çalışmada, arıtılmış atıksuyun özellikle peyzaj sulama amacıyla tekrar kullanıldığı Sharjah Atıksu Arıtma Tesisi (Biyolojik Arıtma+Hızlı Kum Filtrasyonu+UV Dezenfeksiyon sistemi içeren) atıksularında tanımlanan 10 farmasotik için insan sağlığı risk değerlendirmesi yapmayı amaçlamışlardır. Çalışmada risk değerlendirmesi alıcıları; yeşil alanlarda oynayan çocuklar, yetişkin peyzaj çalışanları ve arıtılmış atıksu ile sulanan atletik ve golf sahalarındaki yetişkin kullanıcılar olarak tanımlanmıştır. Alıcıların 10 farmasotiğin her birinin hem dermal hem de yutmaya maruz kalma risklerini değerlendirmek için kullanılan risk değerlendirme modelinde, tüm farmasotikler için güvenli maruz kalma risk oranı RO $<1$ olarak belirlenmiştir. Bu durum tüm alıcılar için ilaçlarla ilgili sağlık risklerinin algılanmadığı anlamına gelmektedir. İncelenen farmasotikler arasında en yüksek risk oranı sıralaması; asetaminofen, metoprolol, siprofloksasin, eritromisin, ofloksasin, sülfadiazin, sülfametoksazol, sülfapiridin, risperidon ve sülfometazin şeklindedir. İlaçlardan en fazla etkilenen alıcı grubu ise peyzaj çalışanları olarak belirlenmiştir.

Kalıcılıklarından dolayı, bazı organik mikrokirleticiler, insan sağlığı ve çevre üzerinde potansiyel önemli etkileri ile toksik olabilir ve biyolojik olarak birikebilirler. Bu biyoakümülasyon tipik olarak bir bileşiğin yüksek lipid çözünürlük özelliği ve uzun bir süre boyunca canlı organizmaların yağ dokularında birikme kabiliyeti ile ilişkilidir. Bu kalıcı bileşik besin zincirini hareket ettirir ve bazı organizma dokularında işlenip metabolize edildiklerinde konsantrasyonları artar, bu da ortamdaki toksisitelerini arttırır [14].

PPCP'lere sürekli maruz kalmak, çevredeki konsantrasyonları düşük olmasına rağmen, sucul ortamlar ve insan sağlığı üzerindeki potansiyel toksisite etkileri nedeniyle kritik bir husustur [47]. Bu konuda Ma ve diğ. [13] tarafindan yapılan çalışmaya göre tespit edilen tüm mikrokirletici maddeler ile ilişkili kanserojen ve kanserojen olmayan riskler ihmal edilebilir düzeyde olsa da, PPCP'lerin tehlike oranları, toplam tehlike oranının \%92.03-97.23'ünü oluşturmaktadır. Buna rağmen PPCP'lerin peyzaj gölündeki ekolojik süreçler (adsorpsiyon, biyolojik bozulma, fotoliz, su bitkilerinin ve hayvanlarının aracılık ettiği diğer faaliyetler) boyunca kayda değer şekilde giderimi ile geri kazanılmış su kullanımının güvenliğinin arttırılabileceği ve mikrokirleticilerin neden olduğu sağlık riskinin azaltılabileceği çalışmada tespit edilen bir diğer husustur.

126 adet PPCP'nin ileri arıtma proseslerinde yaşam döngüsü değerlendirmesinin yapıldığı bir çalışmada; 17ß-estradiol, amoksisilin, misk keton, irgarol, 17 $\alpha$-etinilestradiol, oktilfenol, bendroflumetiazit, ofloksasin, izoproturon ve triklosan kirleticilerinin tatlı su ekotoksisitesi için en yüksek konsantrasyon faktörü değerlerine katkıda bulunduğu belirlenmiştir. İnsan toksisitesine katkısı yüksek olan kirleticiler ise $17 \alpha$-etinilestradiol, sertralin, $17 \beta$-estradiol, estron, diklofenak, paroksetin, terbutirin, diazepam, atorvastatin ve tonalidtir. Ayrıca, tatlı su ekotoksisitesi insan toksisitesinden çok daha yüksek bulunmuştur. Çünkü insan vücudu PPCP'lere tatlı sulardan daha toleranslıdır [47].

Papaioannou ve diğ. [55] tarafından yapılan çalışmada; atıksu arıtma tesisi çıkış suları ile sulanan bir serada toprakta ve pancar bitkisinin yenilebilir kısmında 7 farklı farmasotik (kafein, bisoprolol, karbamazefin, klaritromisin, metoprolol, sülfametoksazol ve trimetoprim) arasındaki etkileşimler incelenmiştir. Atıksuyun yeniden kullanımı ile toprakta birikmiş PPCP'ler arasındaki etkileşimlerin \%99 sinerjistik olduğu; PPCP'lerin interaktif kapasitesindeki değişkenliğin, büyük olasılıkla her PPCP’nin spesifik kimyasal özelliklerinden kaynaklandığı çalışmada elde edilen sonuçlar arasındadır.

\section{SULAMA SUYU GERİ KAZANIMINDA ARITMA SEÇENEKLERİ}

İnsanların temas halinde olduğu alanlarda kentsel atıksuların sulama amaçlı geri kazanımında özellikle halk sağlığı bakımından mikrokirleticilerin en iyi şekilde giderilmesi gerekmektedir [2],[36]. Atıksu üzerine Avrupa yönetmelikleri biyolojik oksijen ihtiyacı (BOİ), askıda katı madde (AKM), azot, fosfor, bakteri vb. parametrelerin de yüksek giderim yüzdeleri için gelişmiş arıtma proseslerine ihtiyaç olduğunu bildirmektedir [46]. Bu nedenle sulama ve diğer amaçlarla kentsel atıksuların geri kazanımı ve yeniden kullanımı açısından mutlaka membran teknolojileri, aktif karbon ve ileri oksidasyon prosesi (İOP) gibi ileri arıtım teknolojileri ne ihtiyaç duyulmaktadır [41],[43]. İleri arıtma olarak nitelendirilen üçüncül arıtma; azot, fosfor, ağır metaller, biyolojik olarak parçalanamayan dirençli organikler, bakteri ve virüsleri gidermek için konvansiyonel ikincil arıtma seviyesinin üzerinde bir performans göstermektedir. Bu amaçla kullanılan membran filtrasyon uygulamaları atıksuyun yeniden değerlendirilmesi ve kullanımında diğer fiziksel arıtma teknikleri ile karşılaştırıldığında çeşitli avantajlarından dolayı tercih edilir hale gelmiştir. Ayrıca mikrofiltrasyon (MF), ultrafiltrasyon (UF), nanofiltrasyon (NF) ve düşük basınçlı ters ozmoz (TO) membranları kullanılarak oluşturulan entegre membran sistemleri de geri kazanılmış su kullanımı ile ilgili artış gösteren projelerde ana arıtma prosesi olarak uygulanmaktadır [2],[24],[38],[44].

Sucul çevrede mikrokirleticilerin giderimi hakkında yapılan birçok çalışma, AÇS veya MBR işlemleriyle mikrokirletici maddelerin uzaklaştırılması üzerine odaklanmıştır. Bu iki prosesin mikrokirletici giderim performansı bakımından önemli bir farkı yoktur [11]. Atıksu yeniden kullanımının başarılı bir şekilde gelişmesi, ortaya çıkan mikrokirleticilerle başa çıkabilen modern atıksu arıtma tesislerinin kurulması veya mevcut tesislerin yükseltilmesi ile yakın ilişki içindedir. Mikroorganizmalar 
dahil birçok partikülü sudan uzaklaştırdığı için çok işlevli ve uygun maliyetli membran filtrasyon yöntemleri ham atıksuya doğrudan uygulanan yenilikçi teknolojilerden biridir [8]. Her ne kadar geleneksel atıksu arıtma işlemleri ile bir miktar giderilse dahi kalıntı PPCP'ler ikincil arıtılmış atıksularda bulunmaktadır. Gelişmiş atıksu arıtma teknolojilerinin, kalıntı PPCP’lerin daha yüksek verimde elimine edilmesi için büyük bir potansiyele sahip olduğu kanıtlanmıştır [47].

Bunun yanında membran filtrasyon ve İP gibi hibrit sistemlerin, eşzamanlı ayırma ve parçalanma mekanizmalarına sebebiyet vermesi muhtemeldir. Geleneksel membran filtrasyon prosesleri ile kirleticilerin çoğu giderilebilir, ancak arıtılmış suda en küçük, bozulmamış ve stabilleştirilmiş farmasotik atıklar kalabilmektedir. İOP ise arıtılmış atıksuda kalan biyolojik parçalanmaya dirençli ve toksik bileşikleri çeşitli yan ürünlerle birlikte özellikle hidroksil radikalleri aracılığıyla son ürünlere dönüştürebilme yeteneğine sahiptir. Membran prosesler ile İOP'lerinin atıksudaki farmasotik kalıntıların ortadan kaldırılmasında tamamlayıcı bir etki göstererek membran performansını da arttıran hibrit sistem uygulamaları son birkaç yılda giderek artış göstermiştir [10]. Bu yaklaşım iki prosesin sadece avantajlarını birleştirmekle kalmaz, aynı zamanda birbirlerinin zorluklarını / dezavantajlarını da ortadan kaldırır. Entegre membran filtrasyonu-İOP'leri, farmasotik gibi mikrokirleticilerin su/atıksudan uzaklaştırılması için incelenmiş olan kombine veya sıralı işlemler bütünüdür. Membran filtrasyonu belediye ve endüstriyel su/atıksu arıtımında giderek daha fazla uygulanmakta ve sürdürülebilir su geri kazanımı için uygun fiyatlı bir alternatif sunmaktadır. Bununla birlikte, membran kirlenmesi sorunu ve konsantrenin uygun şekilde bertaraf edilmesi veya arıtılması ihtiyacı bu teknikte ciddi bir problemdir [48],[49]. Öte yandan İOP, toksik olmayan ve biyolojik olarak parçalanabilen daha küçük moleküllerin oluşumuna kadar birçok kirleticiyi gideren çevre dostu kimyasal, fotokimyasal veya elektrokimyasal yöntemlerdir. Ancak bu proseste ana kirleticilerden daha zararlı toksik yan ürünler oluşabilmekte ve bunların sucul ortamdan uzaklaştırılması için tamamlayıcı işlemlere ihtiyaç duyulmaktadır. Kombine membran filtrasyonu-İOP gibi hibrit sistemler bu tamamlayıcı etkiyi sağlamaktadır [10],[49].

Çeşitli kaynaklardan sürekli olarak atıksu arıtma tesislerine ulaşan yüksek miktardaki mikroplastikler [18], çoğunlukla çöktürme veya yüzeyden sıyırma işlemleri ile atıksudaki katı parçacıkların uzaklaştırılması sırasında tutulmaktadır. Daha küçük mikroplastikler atıksu arıtma tesislerinden alıcı ortamlara kaçabilmektedir [15]. Yapılan çalışmalarda mikroplastiklerin yaklaşık \%35-59'unun ön arıtma sırasında atıksudan uzaklaştırılabileceği ve \%50-98'inin ise birincil arıtma ile giderilebileceği bildirilmektedir. İkincil arıtma, atıksudaki mikroplastikleri \%0.2-14'e kadar, üçüncül arıtma ise \%0.2-2'ye kadar gidermektedir [18].

Talvitie ve diğ. [50] yaptıkları çalışmada, 4 farklı belediye atıksu arıtma tesisi çıkış suyundan MBR ile \%99.9, hızlı kum filtrasyonu ile $\% 97$, çözünmüş hava flotasyonu ile $\% 95$ ve diskfiltre ile $\%$ 40-98.5 mikroplastik giderim verimi elde etmişlerdir. Ancak üçüncül arıtma prosesleri tarafından mikroplastiklerin uzaklaştırılma etkinliğinin güvenilir bir şekilde değerlendirilmesi için ön-arıtma ve ikincil arıtma proseslerinin değerlendirilmesi için gerekenden daha büyük numune alma hacimleri gerekmektedir [18].

Arıtılmış kentsel suların tarımsal kullanımında tarım işçilerinin sağlığı ile birlikte en önemli endişeler; çevre ve insan sağlığı yönleri bir başka deyişle üretilen yiyeceklerin kalite ve güvenliği ile ilgilidir. Diğer kaygılar topraktaki infiltrasyon hızı ve tuzluluk, ağır metal birikimi ve nütrientlerin yol açtığı kirliliktir. Bu endişeleri ortadan kaldırmak ve özellikle tarımsal üretim için uygun çıkış suları üretmek için kesin çözüm, ileri arıtma tekniklerinin yaygınlaştırılmasıdır. Kentsel atıksuların sulama suyu üretimi için kullanımında uygulanan arıtma teknolojileri Tablo 1'de gösterilmektedir [33].

Ma ve diğ. [13] tarafindan yapılan çalışmada; evsel atıksudan alınan örnekler anaerobik-anoksik-oksik üniteyi takiben membran biyoreaktör içeren $\mathrm{A}^{2} \mathrm{O}-\mathrm{MBR}$ sisteminden geçirilip daha sonra çevre düzenlemesi, tuvalet temizleme, yol yıkama, bahçe vb. kullanılmak üzere bir peyzaj gölünde toplanmıştır. Sistemde alınan örneklerde 58 organik mikrokirletici, 13 PAH, 16 fenol, 3 pestisit ve 26 PPCP tespit edilmiştir. A ${ }^{2} \mathrm{O}$ prosesi süresince $\% 51,43 \mathrm{PAH}, \% 13,3-100$ aralığında ise benzo(b)fluoranten hariç diğer önemli kimyasallar giderilmiştir. MBR arıtma prosesi süresince PAH giderimi oldukça düşüktür (\%14,81). $\mathrm{A}^{2} \mathrm{O}-$ MBR prosesi sonrası ise pestisit ve fenol giderim verimi $>\% 80$, PPCP giderim verimi ise orta düzeydedir $(\% 56,85)$. Peyzaj gölünde biriktirilen suyun ekolojik süreçten geçmesiyle ise PPCP'lerin daha da yüksek verimde uzaklaştırıldığı görülmüştür.

Vatankhah ve diğ. [51] yaptıkları çalışmada; US-Nevada'da üçüncül arıtmadan temin ettikleri geri kazanılmış atıksuyu pilot ölçekte dizayn edilen ozon-granül aktif karbon $\left(\mathrm{O}_{3} / \mathrm{GAC}\right)$ sisteminden geçirerek 16 mikrokirleticinin giderimini araştırmışlardır. Ozonlama ile I. Grup mikrokirletici (triklosan, sülfametoksazol, karbamazefin, trimetoprim ve naproksen) için $0,3 \mathrm{mg} \mathrm{O} 3 / \mathrm{mg}$ DOC (çözünmüş organik karbon)'de >\%96, 0,5 ve 0,85 $\mathrm{mg} \mathrm{O}_{3} / \mathrm{mg}$ DOC'de ise >\%98 giderim verimi elde edilmiştir. II. Grup gemfibrozil ve fluoksetin mikrokirleticileri I. Gruba göre daha düşük verimde giderilmiştir $\left(0,3 \mathrm{mg} \mathrm{O}_{3} / \mathrm{mg}\right.$ DOC'de $\% 83 \pm 1.8$ gemfibrozil, $\% 76 \pm 1.9$ fluoksetin; $0,5 \mathrm{mg} \mathrm{O} 3 / \mathrm{mg}$ DOC'da $\% 89 \pm 1.0$ gemfibrozil, \%94 \pm 1.2 fluoksetin; $0,85 \mathrm{mg} \mathrm{O} / \mathrm{mg}$ DOC'de >\%98 gemfibrozil ve fluoksetin). III. grup mikrokirletici için ise (DEET, primidon, sükraloz, meprobamat ve N-Nitrozomorfolin) I ve II. grup mikrokirleticiye göre çok daha düşük verimde giderim sağlanmıştır. Adsorpsiyon deneylerinde $0,5 \mathrm{gr} / \mathrm{L}$ granül aktif karbon dozunda gemfibrozil dışındaki diğer mikrokirleticiler için \%3-12 giderim verimi elde edilmiştir. Naproksen, trimetoprim ve gemfibrozil için giderim verimleri sırasıyla $\% 43, \% 50$ ve $\% 56$ olarak belirlenmiştir. Çalışma sonuçlarına göre; sadece ozonlama veya adsorpsiyonla TCEP, sükraloz ve meprobamat mikrokirleticileri için iyi bir giderim sağlandığı, buna kıyasla $\mathrm{O}_{3} / \mathrm{GAC}$ 'de bir katalizör olarak GAC'nin mikrokirletici giderimine katkıda bulunmadığı ve 20 saatin üzerinde bir işletme süresi sağlandığında sükraloz ve N-nitrozomorfolin haricindeki belirli mikrokirleticilerin azaltıldığı tespit edilmiştir. 
Tablo 1. Sulama suyu üretimi için uygulanan arıtma teknolojileri [33]

\begin{tabular}{|c|c|c|c|}
\hline Teknoloji & Arıtma Yeteneği & Avantajları & Dezavantajları \\
\hline $\mathrm{NaOCl}$ & $\begin{array}{l}\text { Yüksek bakteri yok edici etki; EC giderimi yok, } \\
\% 10-\mathrm{NO}_{3} \text { giderimi ve } \% 18-\mathrm{PO}_{4} \text { giderimi }\end{array}$ & Düşük işletme maliyetleri & $\begin{array}{l}\text { Yüksek işletilebilme, yüksek } \\
\text { yan ürün oluşumu, orta } \\
\text { yatırım maliyeti }\end{array}$ \\
\hline Ozon & Yüksek bakteri yok edici etki & Düşük yan ürün oluşumu & $\begin{array}{l}\text { Yüksek işletilebilme, orta } \\
\text { işletme maliyetleri, yüksek } \\
\text { yatırım maliyetleri }\end{array}$ \\
\hline UV & Yüksek bakteri yok edici etki & $\begin{array}{l}\text { Yan ürün oluşumu yok, düşük } \\
\text { işletme maliyetleri }\end{array}$ & $\begin{array}{l}\text { Yüksek işletilebilme, orta } \\
\text { yatırım maliyeti }\end{array}$ \\
\hline $\mathrm{TiO}_{2}$ & Koliformların yüksek inaktivasyonu & $\begin{array}{l}\text { Güneş fotokatalizi durumunda } \\
\text { muhtemel yenilenebilir enerji } \\
\text { kullanımı, ucuz katalizörler ve } \\
\text { tesislerin kullanımı, yan ürün } \\
\text { oluşum yok }\end{array}$ & $\begin{array}{l}\text { Kalıntı bakteri yok edici etki } \\
\text { ve yavaş kinetik davranış } \\
\text { eksikliği }\end{array}$ \\
\hline $\begin{array}{l}\text { Havuzlar, yapay } \\
\text { sulak alanlar }\end{array}$ & $\begin{array}{l}\text { EC giderimi yok, bakteri giderim verimi 1-6 log } \\
\text { birim arasında bakteri taşınma, } \mathrm{NH}_{4} \\
\text { giderimi }>\% 70 \text {, TP giderimi }>\% 65 \text {, için } \% 55 \mathrm{Cr} \text {, } \\
\% 25-35 \mathrm{Ni}, \% 25-87 \mathrm{Zn}, \% 9 \mathrm{Cu}, \% 33 \mathrm{Cd}, \% 75 \\
\text { Co giderimleri }\end{array}$ & $\begin{array}{l}\text { Düşük bakım maliyetleri ve enerji } \\
\text { kullanımı, yan ürün oluşumu yok }\end{array}$ & $\begin{array}{l}\text { Meteorolojik koşullara bağlı } \\
\text { olarak verimlilik, büyük alan } \\
\text { ihtiyacı }\end{array}$ \\
\hline Orta filtrasyon & $\begin{array}{l}\text { Fekal koliform giderimi: 0.6-1.5 log-birim, } \\
\mathrm{TN}: 5 \mathrm{mg} / \mathrm{L}, \mathrm{PO}_{4}-\mathrm{P}: 4-10 \mathrm{mg} / \mathrm{L} \text { (Nihai } \\
\text { konsantrasyon) }\end{array}$ & $\begin{array}{l}\text { Düşük yatırım maliyeti, düşük } \\
\text { işletme maliyetleri }\end{array}$ & Fekal koliform giderimi düşük \\
\hline Membran filtrasyon & $\begin{array}{l}\text { Bakteriyel giderim: > } 5 \text { logaritmik birim, } \\
\text { gözenek büyüklüğüne göre nütrient giderimi, } \\
\text { TO ile } \% 90 \mathrm{EC}, \% 83 \mathrm{Na} \text { ve } \% 80 \mathrm{Cl} \text { giderimi, } \\
\text { ayrıca nütrient eş zamanlı olarak sodyum } \\
\text { iyonları ve çift değerli katyon giderimi sağlanır. } \\
\text { NF nütrientleri içeren tek değerli iyonlardan çok } \\
\text { çift değerli iyonları rejekt eder, Cr için } \% 75 \text {, As } \\
\text { için }>\% 80 \text { giderim sağlar. }\end{array}$ & $\begin{array}{l}\text { Eşzamanlı dezenfeksiyon ile EC } \\
\text { ve ağır metal giderimi }\end{array}$ & $\begin{array}{l}\text { Yüksek yatırım masrafları, } \\
\text { yüksek işletme maliyeti }\end{array}$ \\
\hline Elektroliz & $\begin{array}{l}\text { Düşük akım yükleme ile etkili dezenfeksiyon } \\
\left(0.9 \mathrm{kA} \mathrm{hm}^{-3} \text { 'ün altında) }\right.\end{array}$ & $\begin{array}{l}\text { Geniş mikroorganizma } \\
\text { spektrumunu öldürme etkisine } \\
\text { sahip }\end{array}$ & $\begin{array}{l}\text { Perkloratların önemli miktarda } \\
\text { formasyonu }\end{array}$ \\
\hline
\end{tabular}

Başka bir çalışmada, pestisitlerin giderimi için ileri arıtma yöntemi olarak ozonla oksidasyon ve GAC ile filtrasyonun etkili olduğu, ancak gelişmiş oksidasyon proseslerinde aktif karbon doygunluğu ve toksik kimyasal yan ürünlerin oluşumu gibi problemlerin gelişebileceği belirtilmektedir [8].

Semreen ve diğ. [52] tarafından yapılan çalışmada, "Biyolojik Arıtma+Hızlı Kum Filtrasyonu+UV Dezenfeksiyon Sistemi" içeren Birleşik Arap Emirlikleri Sharjah Atıksu Arıtma Tesisi giriş ve çıkıș suyunda 10 farklı farmasotik için elde edilen giderim verimleri \%31-96 arasında değişmektedir. Tesiste arıtma sonrası en yüksek giderimin asetaminofen, en düşük giderimin ise eritromisin için elde edildiği belirtilmektedir.

Wang ve diğ. [7] tarafindan yapılan çalışmada, Çin'de bulunan belediye atıksu arıtma tesislerinde uygulanan ileri arıtma yöntemlerinden pihtılaşma/sedimantasyon-kum filtrasyonu ile \%36.9 $\% 5.9$, UV bazlı proses ile $\% 47.5 \pm \% 19.4$, ozonlama ile $\% 78.3 \pm \% 2.2$ ve TO prosesi ile \%99.3 mikrokirletici giderim verimi elde edilmiştir. Mikrokirleticilerin tipine bağlı olarak ikincil arıtma süresince ise giderim verimi ortalama $\% 87.0 \pm \% 5.9$ olmuştur.

Membran ayırma (NF90 ve BW30 membranlar1 ile) ve fotokatalitik oksidasyonun $\left(\mathrm{TiO}_{2}\right.$ ya da $\left.\mathrm{Fe}_{2} \mathrm{O}_{3} / \mathrm{SBA}-15\right)$ birleştirilerek, atıksulardan farmasotik kirleticilerin gideriminin incelendiği bir çalışmada, bu kombinasyonun sadece farmasotiklerin etkili bir şekilde atıksudan ayrılmasını sağlamakla kalmayıp, aynı zamanda foto-oksidasyon yoluyla bozunmasını da sağladığı belirlenmiştir [53].

Başka bir çalışmada süspanse $\mathrm{TiO}_{2}$ ve batık bir ultrafiltrasyon hollow fiber membrandan oluşan fotokatalitik reaktörde, 33 iz organik kirletici maddenin fotokatalitik parçalanması değerlendirilmiş, 1 saat reaksiyondan sonra 18 adet bileşiğin tamamen 
bozulduğu, 14 adet bileşikten oluşan bir grubun \%50-88 oranında giderildiği ve tris(2-kloroetil)fosfat miktarının ise azaltılamadığı tespit edilmiştir [54]. Zhou ve diğ.[48] tarafindan; belediye atıksu arıtma tesisi terz ozmoz konsantresindeki organik kirleticilerin giderimi için lab-ölçekte 4 basit ileri oksidasyon işlemi [heterojen fotokatalitik oksidasyon, sonolisis, ozonlama $\left(\mathrm{O}_{3}\right)$ ve $\mathrm{H}_{2} \mathrm{O}_{2}$ oksidasyonu] ve bunların kombinasyonları araştırılmıştır. Çalışmada TO konsantresindeki organik kirleticilere ait en iyi giderim veriminin (\%95), 6 saatlik sürede $\mathrm{FeCl}_{3}$ koagülasyon + fotokataliz $\left(\mathrm{UVC}_{\mathrm{TiO}}\right)$ entegrasyonu ile sağlandığı belirlenmiştir.

\section{SONUÇLAR}

Atıksuların geri kazanımında arıtma yönteminin seçimi, mevcut su kaynaklarının durumu, konum, arazi, kültür gibi birçok sosyo-ekonomik faktöre bağlıdır. Aynı şekilde atıksu geri kazanım politikaları ve düzenlemeleri de halkın bilinçlendirilmesi ile birlikte önemlidir. Bazı bölgelerde suyun geri kazanımına olan ilginin artmasına bağlı olarak, mevcut atıksu arıtma tesislerinin modifiye edilmesi veya yeni gelişmiş atıksu arıtma tesislerinin inşa edilmesi atıksuların yeniden kullanım politikalarının ilk hedefi olmalıdır. Yeni atıksu arıtma tesisleri yapımında mikrokirleticilerin varlığı ve giderimine yönelik ileri arıtma seçenekleri mutlak surette dikkate alınmalıdır. Atıksu karakterizasyonuna bağlı olarak, sulama ve diğer amaçlarla kentsel atıksuların geri kazanımı ve yeniden kullanımı için membran ve ileri oksidasyon gibi teknolojiler ve bunların hibrit uygulamaları yaygınlaştırılmalıdır. Bu süreçte aktif olarak rol alacak tüm bilim insanlarının en ince ayrıntıya kadar yapılacak değişiklikleri planlaması, uygulama sürecinde ise olası makro ve mikrokirleticilerin sürekli olarak izlenerek arıtılmış atıksuların geri kazanım sürecine dahil edilmesi halk ve çevre sağlığı açısından önem teşkil etmektedir. Bununla birlikte özellikle mikrokirleticilerle ilgili deşarj standartlarının ülkemizdeki sulama ile ilgili yönetmeliklerle net bir şekilde ilişkilendirilmesi atıksuların sulamada kullanımı üzerine var olan endişeleri ortadan kaldıracaktır.

\section{KAYNAKLAR}

[1] Çevre ve Şehircilik Bakanlığı, "Kentsel Atıksu Arıtımı Yönetmeliği,” Ankara, Türkiye, R.G. Tarih-No: 08.01.200626047, 2006.

[2] J. L. Acero, F. J. Benitez, A. I. Leal, F. J. Real, F. Teva, "Membrane filtration technologies applied to municipal secondary effluents for potential reuse," Journal of Hazardous Materials, vol. 177, no. 1-3, May., pp. 390-398, 2010.

[3] F. Zanetti, G. De Luca, R. Sacchetti, "Performance of a full-scale membrane bioreactor system in treating municipal wastewater for reuse purposes," Bioresource Technology, vol. 101, no. 10, May., pp. 3768-3771, 2010.

[4] E. Can Doğan, A. Yaşar, Ü. Şen, C. Aydıner, "Water recovery from treated urban waswater by ultrafiltration and reverse osmosis for landscape irrigation," Urban Water Journal, vol. 13, no. 6, Jan., pp. 553-568, 2016.

[5] P. Jin, X. Jin, X. C. Wang, X. Shi, "An analysis of the chemical safety of secondary effluent for reuse purposes and the requirement for advanced treatment," Chemosphere, vol. 91, no. 4, Apr., pp. 558-562, 2013.

[6] N. R. Mizyed, "Challenges to treated wastewater reuse in arid and semi-arid areas," Environmental Science Policy, vol. 25, Jan., pp. 186-195, 2013.

[7] J. Wang, Z. Tian, Y. Huo, M. Yang, X. Zheng, Y. Zhang, "Monitoring of 943 organic micropollutants in wastewater from municipal wastewater treatment plants with secondary and advanced treatment processes," Journal of Environmental Sciences, vol. 67, May., pp. 309-317, 2018.

[8] B. Maryam ve H. Büyükgüngör, "Wastewater reclamation and reuse trends in Turkey: Opportunities and challenges," Journal of Water Process Engineering, vol. 30, Aug., 100501, 2019.

[9] P. Verlicchi, A. Galletti, M. Petrovic, D. Barcelo, "Hospital effluents as a source of emerging pollutants: An overview of micropollutants and sustainable treatment options," Journal of Hydrology, vol. 389, no. 3-4, Aug., pp. 416-428, 2010.

[10] N. Rosman, W. N. W. Salleh, M. A. Mohamed, J. Jaafar, A. F. Ismail, Z. Harun, "Hybrid membrane filtrationadvanced oxidation processes for removal of pharmaceutical residue," Journal of Colloid and Interface Science, vol. 532, Dec., pp. 236-260, 2018.

[11]C. Grandclément, I. Seyssiecq, A. Piram, P. Wong-Wah-Chung, G. Vanot, N. Tiliacos, N. Roche, P. Doumenq, "From the conventional biological wastewater treatment to hybrid processes, the evaluation of organic micropollutant removal: A Review," Water Research, vol. 111, Mar., pp. 297-317, 2017.

[12] A. Yaşar, E. Can Doğan, A. Arslan, "Hastane atıksularında makro ve mikro kirleticiler ve arıtma seçenekleri," Erciyes Üniversitesi Fen Bilimleri Enstitüsü Dergisi, vol. 29, no. 2, Apr., pp. 144-158, 2013.

[13]X. Y. Ma, X. C. Wang, X. C. Wang, Y. Wang, D. Wang, H. H. Ngo, "Micropollutants removal and health risk reduction in a water reclamation and ecological reuse system," Water Research, vol. 138, July, pp. 272-281, 2018. 
[14]P. Burkhardt-Holm, "Linking water quality to human health and environment: The fate of micropollutants, institute of water policy," Institute of Water Policy, National University of Singapur, pp. 1-62, 2011.

[15] J. C. Prata, "Microplastics in wastewater: State of the knowledge on sources, fate and solutions," Marine Pollution Bulletin, vol. 129, no. 1, Apr., pp. 262-265, 2018.

[16] M. Yurtsever, "Küresel plastik kirliliği nano-mikroplastik tehlikesi ve sürdürülebilirlik," Çevre Bilim ve Teknoloji Dergisi, no. 1, ISBN:978-605-7594-06-8, pp. 171-197, 2018.

[17]Z. Long, Z. Phan, W. Wang, J. Ren, X. Yu, L. Lin, H. Lin, H. Chen, X. Jin, "Microplastic abundance, characteristics and removal in wastewater treatment plants in a Coastal City of China," Water Research, vol. 155, Feb., pp. 255-265, 2019.

[18] J. Sun, X. Dai, Q. Wang, M. C. M. van Loosdrecht, B-J. Ni, "Microplastics in wastewater treatment plants: Detection, occurrence and removal," Water Research, vol. 152, Jan., pp. 21-37, 2019.

[19] The European Parliament and the Council of the European Union, Directive 2000/60/EC of the European Parliament and of the Council of 23 October 2000 establishing a framework for Community action in the field of water policy, Annex-X, 2000.

[20] “Yerüstü Su Kalitesi Yönetmeliği ve Ekleri,” Ankara, Türkiye, R.G. Tarih ve Sayı: 30.11.2012-28483, 2012.

[21] "Yüzeysel Su Kalitesi Yönetimi Yönetmeliğinde Değişiklik Yapılmasına Dair Yönetmelik ve Ekleri,” Ankara, Türkiye, R.G. Tarih ve Sayı: 10.08.2016-29797, 2016.

[22] M. O. Barbosa, N. F. F. Moreira, A. R. Ribeiro, M. F. R. Pereira, A. M. T. Silva, "Occurrence and removal of organic micropollutants: An overview of the watch list of EU Decision 2015/495," Water Research, vol. 94, May, pp. $257-$ 279, 2016.

[23] J, Radjenovic, M. Petrovic, F. Ventura, D. Barcelo, "Rejection of pharmaceuticals in nanofiltration and reverse osmosis membrane drinking water treatment," Water Research, vol. 42, no. 14, Aug., pp. 3601-3610, 2008.

[24] K. Chon, S. J. Kim, J. Moon, J. Cho, "Combined coagulation-disk filtration process as a pretreatment of ultrafiltration and reverse osmosis membrane for wastewater reclamation: An autopsy study of a pilot plant," Water Research, vol. vol. 46, no. 6, Apr., pp. 1803-1816, 2012.

[25] P. Bhattacharya, S. Ghosh, A. Mukhopadhyay, "Efficiency of combined ceramic microfiltration and biosorbent based treatment of high organic composite wastewater: An approach for agricultural reuse," Journal of Environmental Chemical Engineering, vol. 1, no. 1-2, June, pp. 38-49, 2013.

[26] C. Furlong, S. De Silva, K. Gan, L. Guthrie, R. Considine, "Risk management, financial evaluation and funding for wastewater and stormwater reuse projects," Journal of Environmental Management, vol. 191, Apr., pp. 83-95, 2017.

[27]G. Murtaza, A. Ghafoor, M. Qadir, "Irrigation and soil management strategies for using saline-sodic water in a cottonwheat rotation," Agricultural Water Management, vol. 81, no. 1-2, Mar., pp. 98-114, 2006.

[28] C. Park, S-W. Hong, T. Hak Chung, Y-S. Choi, "Performance evaluation of pretreatment processes in integrated membrane system for wastewater reuse," Desalination, vol. 250, no. 2, Jan., pp. 673-676, 2010.

[29]F. Pedrero, I. Kalavrouziotis, J. J. Alarcon, P. Koukoulakis, T. Asano, "Use of treated municipal wastewater in irrigated agriculture-review of some practices in Spain and Greece," Agricultural Water Management, vol. 97, no. 9, Sep., pp. 1233-1241, 2010.

[30] A. Kajenthira, A. Siddiqi, L. D. Anadon, "A new case for promoting wastewater reuse in Saudi Arabia: Bringing energy into the water equation," Journal of Environmental Management, vol. 102, July, pp. 184-192, 2012.

[31]S. Bunani, E. Yörükoğlu, G. Sert, Ü. Yüksel, M. Yüksel, N. Kabay, "Application of nanofiltration for reuse of municipal wastewater and quality analysis," Desalination, vol. 315, Apr., pp. 33-36, 2013.

[32] N. B. Goodman, R. J. Taylor, Z. Xie, Y. Gozukara, A. Clements, "A feasibility study of municipal wastewater desalination using electrodialysis reversal to provide recycled water for horticultural irrigation," Desalination, vol. 317, May, pp. 77-83, 2013.

[33] D. Norton-Brandao, S. M. Scherrenberg, J. B. van Lier, "Reclamation of used urban waters for irrigation purposes - A review of treatment technologies," Journal of Environmental Management, vol. 122, June, pp. 85-98, 2013.

[34] S. Shanmuganathan, S. Vignesvaran, T. V. Nguyen, P. Loganathan, J. Kandasamy, "Use of nanofiltration and reverse osmosis in reclaiming micro-filtered biologically treated sewage effluent for irrigation," Desalination, vol. 364, May, pp. 119-125, 2015.

[35]D. M. Revitt, E. Eriksson, E. Donner, "The implications of household greywater treatment and reuse for municipal wastewater flows and micropollutant loads," Water Research, vol. 45, no. 4, Feb., pp. 1549-1560, 2011.

[36] L. Semerjian, A. Shanableh, M. H. Semreen, M. Smarai, "Human health risk assessment of pharmaceuticals in treated wastewater reused for non-potable applications in Sharjah, United Arab Emirates," Environment International, vol. 121, no. 1, Dec., pp. 325-331, 2018.

[37] L. Fan, T. Nguyen, F. A. Roddick, J. L. Harris, "Low pressure membrane filtration of secondary effluent in water reuse: pre-treatment for fouling reduction," Journal of Membrane Science, vol. 320, no. 1-2, July, pp. 135-142, 2008. 
[38]P. Xu, C. Bellona, J. E. Drewes, "Fouling of nanofiltration and reverse osmosis membranes during municipal wastewater reclamation: Membrane autopsy results from pilot scale investigations," Journals of Membrane Science, vol. 353, no. 1-2, May, pp. 111-121, 2010.

[39] S. Bakopoulou, C. Emmanouil, A. Kungolos, “Assessment of wastewater effluent quality in Thessaly Region, Greece, for determining its irrigation reuse potential," Ecotoxicology and Environmental Safety, vol. 74, no. 2, Feb., pp. 188194, 2011.

[40] M. Rygaard, P. J. Binning, H. J. Albrectsen, "Increasing urbanwater self-sufficiency: New era, new challenges," Journal of Environmental Management, vol. 92, no. 1, Jan., pp. 185-194, 2011.

[41]E. Agrafioti ve E. Diamadopoulos, "A strategic plan for reuse of treated municipal wastewater for crop irrigation on the island of Crete," Agricultural Water Management, vol. 105, Mar., pp. 57-64, 2012.

[42]L. D. Nghiem ve S. Hawkes, "Effects of membrane fouling on the nanofiltration of pharmaceutically active compounds (PhACs): mechanisms and role of membrane pore size," Separation and Purification Technology, vol. 57, no. 1, Oct., pp. 176-184, 2007.

[43] Çevre ve Şehircilik Bakanlığı, "Su Kirliliği Kontrolü Yönetmeliğgi, Atıksu Arıtma Tesisleri Teknik Usuller Tebliği Ek:7,” Ankara, Türkiye, R.G. Tarih-No: 20.03.2010-27527, 2010.

[44] M. El Tokhy, H. F. Shaalan, A. M. Sharaky, N. M. Abd El-Monem, G. A. Al Bazedi, "Performance analysis of upgrading of secondary treated wastewater by nanofiltration," World Applied Sciences Journal, vol. 25, no. 3, Oct., pp. 384-390, 2013.

[45] I. Michael, L. Rizzo, C. S. McArdell, C. M. Manaia, C. Merlin, T. Schwartz, C. Dagot, D. Fatta-Kassinos, "Urban wastewater treatment plants as hotspots for the release of antibiotics in the environment: A review," Water Research, vol. 47, no. 3, Mar., pp. 957-995, 2013.

[46] A. Blstakova, I. Bodik, L. Dancova, Z. Jacubcova, "Domestic wastewater treatment with membrane filtration - two years experience," Desalination, vol. 240, no. 1-3, May, pp. 160-169, 2009.

[47] Y. Li, S. Zhang, W. Zhang, W. Xiong, Q. Ye, X. Hou, C. Wang, "Life cycle assessment of advanced wastewater treatment processes: involving 126 pharmaceuticals and personal care products in life cycle inventory," Journal of Environmental Management, vol. 238, May, pp. 442-450, 2019.

[48] T. Zhou, T-T. Lima, S-S. Chind, A. G. Fane, "Treatment of organics in reverse osmosis concentrate from a municipal wastewater reclamation plant: feasibility test of advanced oxidation processes with/without pretreatment," Chemical Engineering Journal, vol. 166, no. 3, Feb., pp. 932-939, 2011.

[49] S. O. Ganiyu, E. D. van Hullebusch, M. Cretin, G. Esposito, M. A. Oturan, "Coupling of membrane filtration and advanced oxidation processes for removal of pharmaceutical residues: A critical review," Separation and Purification Technology, vol. 156, no. 3, Dec., pp. 891-914, 2015.

[50] J. Talvitie, A. Mikola, A. Koistinen, O. Setala, "Solutions to Microplastic Pollution - Removal of microplastics from wastewater effluent with advanced wastewater treatment technologies," Water Research, vol. 123, Oct., pp. 401-407, 2017.

[51]H. Vatankhah, S. M. Riley, C. Murray, O. Quinones, K. X. Steirer, E. R. V. Dickenson, C. Bellona, "Simultaneous ozone and granular activated carbon for advanced treatment of micropollutants in municipal wastewater effluent," Chemosphere, vol. 234, Nov., pp. 845-854, 2019.

[52] M. H. Semreen, A. Shanableh, L. Semerjian, H. Alniss, M. Mousa, X. Bai, K. Acharya, "Simultaneous determination of pharmaceuticals by solid-phase extraction and liquid chromatography-tandemmass spectrometry: a case study from Sharjah Sewage Treatment Plant,” Molecules, vol. 24, Feb., pp. 633, 2019.

[53]F. Martinez, M. J. Lopez-Munoz, J. Aguado, J. A. Melero, J. Arsuaga, A. Sotto, R. Molina, Y. Segura, M. I. Pariente, A. Revilla, L. Cerro, G. Carenas, "Coupling membrane separation and photocatalytic oxidation processes for the degradation of pharmaceutical pollutants," Water Research, vol. 47, no. 15, Oct., pp. 5647-5658, 2013.

[54] R. L. Fernandez, J. A. McDonald, S. J. Khan, P. Le-Clech, "Removal of pharmaceuticals and endocrine disrupting chemicals by a submerged membrane photocatalysis reactor (MPR)," Separation and Purification Technology, vol. 127, Apr., pp. 131-139, 2014.

[55] D, Papaioannou, P. H. Koukoulakis, M. Papageorgiou, D. A. Lambropoulou, I. K. Kalavrouziotis, "Investigation of pharmaceutical and personal care product interactions of soil and beets (beta vulgaris 1.) under the effect of wastewater reuse," Chemosphere, vol. 238, Jan., 124553, 2020. 